\title{
A CIRCULAR ECONOMY IN WASTE MANAGEMENT CARRYING OUT EXPERIMENTAL EVALUATION OF COMPRESSED STABILIZED EARTH BLOCK USING MUNICIPAL SOLID WASTE INCINERATOR FLY ASH
}

DOI:10.36909/jer.ACMM.16319

\author{
Abinaya $\mathrm{T} \mathrm{L}^{1}$, Balasubramanian $\mathrm{M}^{2 *}$ \\ ${ }^{1}$ School of Architecture and Interior Design, SRM Institute of Science and Technology, India. \\ ${ }^{2}$ *Department of Civil Engineering, SRM Institute of Science and Technology, India.
}

\begin{abstract}
The proper reuse and treatment Municipal solid waste incinerator fly ash is a is current a global concern. MSWI fly ashes possess a high concentration of $\mathrm{SiO}_{2}$, allowing them to be utilized as a raw material in the production of CSEB. This research looks into compressed stabilized earth blocks (CSEBs) that use municipal solid waste incinerator fly ash (MSWIFA) as an alternative to soil-sand mixture and sand. The experiment was divided into two phases: in the first, the effect of municipal solid waste incinerator fly ash on substituting soil-sand mix without affecting original performance, as well as resistance to sulfate attack, was emphasized. The effect of MSWIFA particle size and replacement ratio on replacing natural sand was then investigated. The analysis reveals that including MSWIFA into a soil-sand mixture considerably improved block performance, particularly under wetting-drying cycles and sulfate attack. MSWIFA particle size and replacement ratio have a significant influence on block strength and water absorption. Compressive and flexural strength are improved by the addition of $20 \%$ MSWIFA with a particle size of $0 / 4.75 \mathrm{~mm}$. As a result, the research establishes a new investigation into the environmental recycling of MSWIFA in the context of the circular economy.
\end{abstract}

Keywords: MSWIFA, CSEB, sulfate attack, compressive strength and circular economy.

\section{INTRODUCTION}

Earthen materials are mainly used in developing countries because of their cost efficiency, earthen materials also perform better in terms of strength and durability. Due to its multiple advantages, Earth has been used as a building material and is widely available at less cost[1]. Earthen materials are also an eco-friendly alternative to energy-intensive building materials that improve buildings' carbon footprint. The several buildings made from earth- 
materials are old, yet still solid and rigid[2]. Furthermore, when using land as a construction material the need for skilled labour is not required. Bricks today are seen as one of the main building material [3] [4]. Innovative new building materials that can be locally made and easily constructed will help reduce costs for the housing sector, especially with the lower incoming segments [5]. Stabilized earth appears to be notable among sustainable building techniques. Compressed stabilized earth blocks (CSEBs) have been employed in several countries throughout the past 50 years. CSEBs are produced by compressing a soil moist mixture and the appropriate stabilizer in a high density block in a manually operated press[6]. These CSEBs are 2.5 times larger than normal burned clay bricks and consequently less joint building is faster. Utilization of industrial wastes in construction activities provide social, economic and environmental benefits[7]. Materials such as Fired Clay Brick (FCB)[8], concrete blocks became more and more common around the globe. Consequently, ecofriendly building materials for sustainable development are an essential issue that once again disputes the usage of raw earth. Recently, extensive study has been done to make land a sustainable building material. This has led to the development of Compressed Stabilized Earth Block (CSEB)[9]. Compressed Earth Blocks (CEBs) consist of the high-pressure compression of the soil. In order to prepare the mix for CEB, stabilizers are next added in particular quantities and called CSEB.

A great amount of municipal waste is produced worldwide and its treatment in most countries and regions becomes urgent. The traditional method of disposal is sanitary landfills, which consume land resources while also posing a potential threat to underground water and soil. As a result of the volume reduction and energy recovery from municipal solid waste, incineration is becoming more popular around the world. Approximately $25 \%$ of the entire mass of MSW after incineration is MSWIFA, which must be disposed of in landfills [10]. Recent developments indicate that future advances in resource efficiency are achieved with in a circular economy, trash becomes a resource and completing the loop. The management of solid waste is a significant responsibility globally; our country (India) buries a mound of garbage. The country produces more than 1.50 lakh metric tons of solid waste every day, based on the CPHEEO report. In Chennai, every day, around 5400 MT of garbage waste and 700 MT of construction and Demolition waste is collected. The waste generation by category residential 68\%, Commercial 16\%, School and Institution 14\%, industrial and hospital. The garbage waste is segregated into biodegradable $40 \%$ and non-biodegradable $60 \%$. By burning per ton of non-biodegradable waste, $20 \%$ of ash generated. To reuse solid waste will preserve 
the future environment. The MSWIFA may be a better alternative for construction material. The intention was thus to contribute in the production industries to a circular economy[11].

This research focused on achieving nearly zero-energy buildings by using municipality solid waste. In India, municipality solid waste is dumped in landfills[12]. Reusing municipality solid waste may preserve the environment[13]. Many countries have undertaken recycling programs to assure the MSWIFA, such as aggregates, masonry blocks, highways and as an alternative to natural resources in building[14]. Using MSWIFA as an alternative construction material will improve its energy efficiency and compressive strength. The MSWIFA used as the construction material will increase the thermal comfort of the buildings. As a result of these issues, the authors decided to include MSWIFA in their CSEB preparation. Due to the soil demand, MSWIFA is the best option to replace the soil in manufacturing the CSEB and its also cost efficient [1]. Significant improvements have been seen recently in the use of such waste materials and usage rates vary in different countries from 27 to $90 \%$. It is important to note that the proper use of this trash remains a serious challenge in emerging and impoverished countries. For example, in India, the utilization rate is the lowest (27\%). Therefore, the incorporation of MSWIFA in CSEB might be a viable approach, which not only recycling MSWIFA as raw material and saving clay resource. The socioeconomic context of their native regions has a significant impact on the features of MSWIFA[10]. Therefore, the results of the present investigation may be used to conduct comparative studies of not only science but also socioeconomic interest[15]. The objective in this research was to assess the possible use of MSWIFA for the fabrication of CSEB as a raw material. As a result, we intend to contribute to waste management in a circular economy.

\section{MATERIAL AND METHODS}

\section{Soil}

The utilised soil has been gathered from $0.5-1.5 \mathrm{~m}$ under land level in Auroville, Pondicherry. The Atterberg limits, shrinking limit, free swell index, and conventional proctor compaction tests were used to determine the distribution of soil suitability. Table 1 outlines the index characteristics of the soil with liquid and plastic limitations of $51.78 \%$ and $22.67 \%$. It shows that the soil is quite fine with a $97.12 \%$ fraction of clay and silt. The soil activity is 0.69 which usually indicates active in accordance with mineralogical data. Depending on soil type, the optimum clay content for CEB soils varies between $8.65 \%$ and $22.0 \%$. The distribution of soil in grain size falls outside of the recommended IS 1725 envelope for producing compressed earth blocks. In addition to this, IS 1725 recommended a $30-75 \%$ and 
50-80\% CEB sand concentration. Mixtures with various percentages of sand and soil were therefore made to get the best mixing ratio. A soil-sand ratio mix 30:70 has been selected to achieve maximum dry density, which corresponds to previous studies. The highly fine, grained CSEB earth has a maximum density and compressive strength of 50-60\%.

Table 1. Soil and Reconstitution Soil properties

\begin{tabular}{|l|c|c|}
\hline \multicolumn{1}{|c|}{ Properties } & Soil & Reconstitutes soil \\
\hline Grain Size Distribution & & \\
Silt & $61.45 \%$ & $20.45 \%$ \\
Clay & $35.67 \%$ & $10.67 \%$ \\
Sand & $2.88 \%$ & $61.88 \%$ \\
Atterberg Limit & & \\
Liquid Limit & $51.78 \%$ & $25.7 \%$ \\
Plastic Limit & $25.55 \%$ & $20.8 \%$ \\
Plasticity Index & $22.67 \%$ & $8.2 \%$ \\
Proctor test & & \\
Optimum moisture content & $19.67 \%$ & $21.45 \%$ \\
Maximum dry density & $1820 \mathrm{~kg} / \mathrm{m}^{3}$ & $1923 \mathrm{~kg} / \mathrm{m}^{3}$ \\
& & \\
Shrinkage limit & $18.23 \%$ & $\mathrm{SM}$ \\
IS Soil classification & $\mathrm{CH}$ & - \\
Activity & 0.69 & \\
\hline
\end{tabular}

\section{Municipal solid waste to Municipal solid waste incinerator fly ash}

Every day around 5400 MT of garbage is collected from the Chennai city. Source separation is promoted to reduce the waste coming to the Landfill. The source separated nonbiodegradable (Dry Waste) are dumped in two dumping station. Incineration has overtaken landfilling as the most important option for disposal of the increasing volumes of municipal solid waste (MSW) generated in Chennai. The non-biodegradable MSWI fly ash has high silica, therefore it is suitable for replacement of construction material. In Chennai, there are two Incinerator plant at manali and kodungaiyur north madras. Each plant has capacity of 200T respectively. In 50T plant, production of MSWI fly ash is $2000 \mathrm{~kg}$ per day in each plant. Fig.1. (a) \& (b) MSWI plant, (c) MSWIFA 
(a)

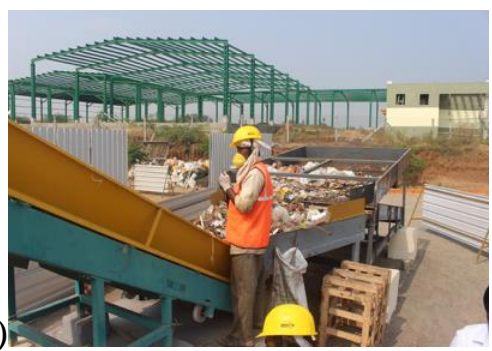

(b)

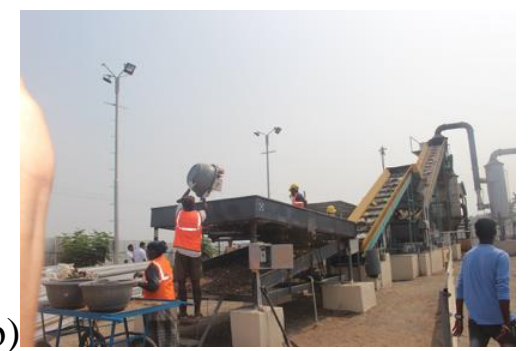

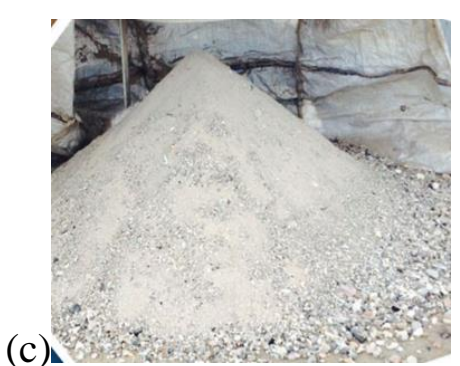

Figure.1. (a) \& (b) Municipal solid waste incinerator plant, (c) MSWIFA

\section{Sand and Municipal solid waste incinerator fly ash}

Municipal solid waste incinerator fly ash collected from local incinerator plant and natural river sand was used. The physical properties of river sand and MSWIFA are presented in Table 2. The chemical properties of MSWIFA are shown in Tables 3.

Table 2. Physical properties of sand and MSWIFA. Table 3 Chemical properties of MSWIFA

\begin{tabular}{|l|l|l|l|}
\hline S.No & Properties & $\begin{array}{l}\text { River } \\
\text { sand }\end{array}$ & MSWIFA \\
\hline 1 & Water absorption & $1.07 \%$ & $14.08 \%$ \\
2 & Specific gravity & 2.7 & 2.4 \\
3 & Fineness modulus & 1.7 & 2.3 \\
4 & Loose bulk & $1400 \mathrm{~kg} / \mathrm{m}^{3}$ & $1105 \mathrm{~kg} / \mathrm{m}^{3}$ \\
5 & density bulk & $1612 \mathrm{~kg} / \mathrm{m}^{3}$ & $1356 \mathrm{~kg} / \mathrm{m}^{3}$ \\
& Compacted buly & \\
& density & & \\
\hline
\end{tabular}

\begin{tabular}{|l|c|}
\hline Components & MSWIFA \\
\hline $\mathrm{SiO}_{2}$ & 64.75 \\
$\mathrm{Al}_{2} \mathrm{O}_{3}$ & 0.78 \\
$\mathrm{Fe}_{2} \mathrm{O}_{3}$ & 0.38 \\
$\mathrm{CaCO}_{3}$ & 14.85 \\
$\mathrm{Mg} \mathrm{O}$ & 0.74 \\
$\mathrm{C}$ & 15.53 \\
$\mathrm{Fe}_{2} \mathrm{O}_{3}$ & - \\
\hline
\end{tabular}

The Fig.2. Shows the SEM analysis of MSWIFA in 6500 magnifications which shows the crystalline nature of the structure similar to the $\mathrm{SiO}_{2}$ raw material in the sand. The indicates there is some pours in the material due to the uneven nature of the material. The microstructure of 12000 magnification shows the particles are much dense it is similar to the sand. The MSWIFA particles distributed equally throughout the matrix, forming a strong bond with the soil-cement matrix. 

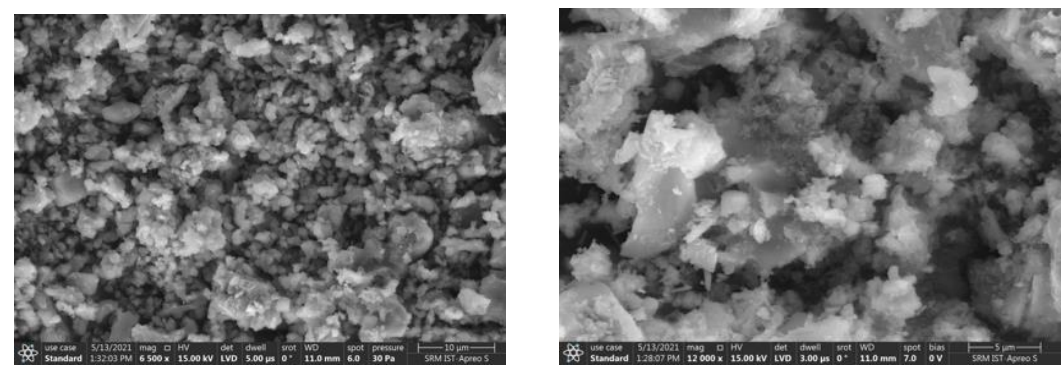

Figure.2. SEM image of MSWIFA

\section{Cement}

The cement used is standard Portland cement of grade 43, which conforms to IS 8112. Because larger soil contents are uneconomical, all mixtures are cement stabilized to a limit of $10 \%$ by soil weight.

\section{Mixture Proportion of CSEB}

A CSEB were prepared in different mix ratio and categorized in phase I and phase II. In phase I, MSWIFA was replaced by $7 \%, 14 \%, 21 \%$ and $28 \%$ of the soil-sand combination. Due to the low clay content of the soil, the addition of MSWIFA was limited to $28 \%$. After this percentage, the block begins to crumble. It can be explained that, immediately after pressing, soil containing low clay levels may have problems handling blocks, because of a lack of initial cohesion[16]. In phase II, sand was replaced by MSWIFA. Tables 4, 5 lists the material proportions of the mixtures for both phase I and phase II.

\begin{tabular}{|c|c|c|c|}
\hline Sample & $\begin{array}{c}\text { MSWIFA } \\
(\%)\end{array}$ & $\begin{array}{c}\text { Soil- } \\
\text { Sand } \\
(\%)\end{array}$ & $\begin{array}{c}\text { Cement } \\
(\%)\end{array}$ \\
& & $\begin{array}{l} \\
\end{array}$ & \\
\hline
\end{tabular}

\begin{tabular}{|l|c|c|c|c|}
\hline Sample & $\begin{array}{c}\text { Cement } \\
(\boldsymbol{\%})\end{array}$ & $\begin{array}{c}\text { Soil } \\
(\boldsymbol{\%})\end{array}$ & $\begin{array}{c}\text { MSWIFA } \\
(\boldsymbol{\%})\end{array}$ & $\begin{array}{c}\text { Sand } \\
(\boldsymbol{\%})\end{array}$ \\
\hline E1 & 10 & 30 & 0 & 70 \\
E3 & 10 & 30 & 14 & 56 \\
E4 & 10 & 30 & 28 & 42 \\
E5 & 10 & 30 & 42 & 28 \\
E6 & 10 & 30 & 56 & 14 \\
\hline
\end{tabular}




\begin{tabular}{|l|c|c|c|}
\hline IF & 0 & 100 & 10 \\
IF7 & 7 & 94 & 10 \\
IF14 & 14 & 88 & 10 \\
IF21 & 21 & 82 & 10 \\
IF28 & 28 & 76 & 10 \\
\hline
\end{tabular}

Table 4. Phase I - Mix proportions

Table 5. Phase II - Mix proportions

CSEBs with dimensions of 240x115x90 mm were manufactured using a hand-operated manual press as shown in Fig. 3(a). The materials used to manufacture the CSEB is sand, soil, cement and municipal solid waste incinerator fly ash with different mix ratio. A sieve with a mesh size of $4.75 \mathrm{~mm}$ is also used to screen the sand and MSWIFA. The soil and sand were initially mixed and the MSWIFA was then added. Further blending continues, following the addition of the cement and thorough mixing until a cohesive mix is obtained. For moulding blocks, the amount of water determined individually by the proctor test for each mix is adopted. To obtain a consistent moisture distribution, the appropriate amount of water was progressively poured into the dry mix and repeatedly rotated around [2]. The wet mixture was then poured in the press mould and any excess material removed from the mould. The combination was then manually compacted, and the block was ejected right away Fig. 3(b). After 24 hours of casting, under the wet gunny bags, the blocks were cured for 28 days and dried in the laboratory for 1 week before testing.

(a)

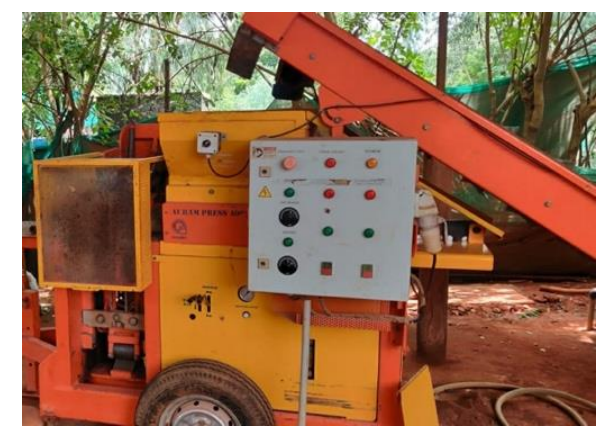

(b)

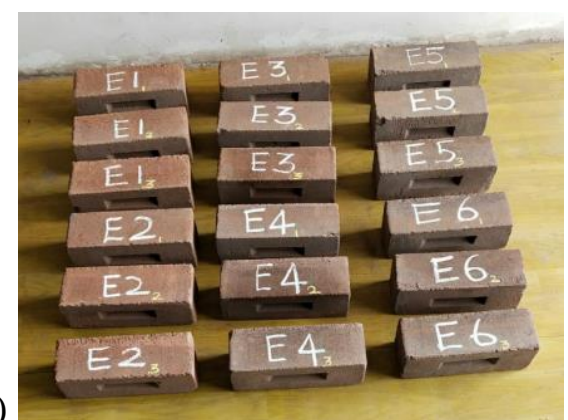

Figure.3. (a) Block making machine, (b) CSEB produced

\section{Block Testing}

Three samples for compressive strength, three samples for water absorption, and three samples for flexural strength were examined for each variation. A compression test with a 100-ton capacity was performed and the ability to deliver uniform force to failure[17]. The CSEB were placed between two steel plate and load was given to determine the compressive strength. CSEB was immersed in water for 24 hours to determine the water absorption according to IS 3495 part II. On phase I, alternating wetting-drying and sulfate attack 
experiments were performed to assess durability and accordance with IS 1725 , an alternate wetting-drying test was carried out. Blocks were dried in an oven at $50^{\circ} \mathrm{C}-60^{\circ} \mathrm{C}$ until they reached a consistent weight and the dry weight was recorded. The blocks were then immersed in room temperature water for 5 hours before being oven dried at $60^{\circ} \mathrm{C} 42$ hours. Taking the blocks from the oven, scrape the wire on each side of the blocks with a force of $1.5 \mathrm{kgf}$ twice. Twelve similar cycles have been performed and the blocks have been dried at $60 \mathrm{C}$ till they achieve their immediate weight[7]. The dried block weight is noticed. Blocks have been oven-dried for 2 days at $100 \mathrm{C}$ and dry weighs have been noted. To test sulphate resistance, blocks were exposed to a sodium sulfate ( $\mathrm{Na} 2 \mathrm{SO} 4)$ solution and then blocks have then been put within the container and the sulfate solution is progressively poured until it reaches a height of $2 \mathrm{~cm}$ to $3 \mathrm{~cm}$ from the base of the block's, as shown in Fig. 4. Samples were removed and weighted after 1 week from the solution [16].

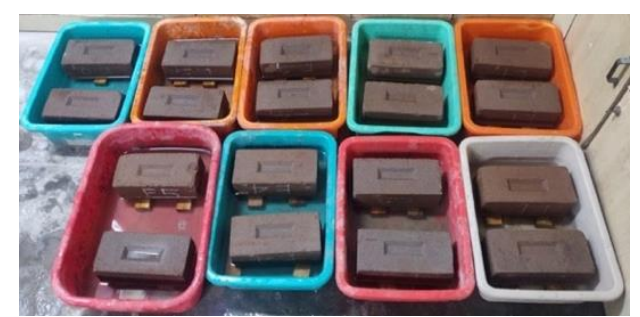

Figure.4. Sulfate attack test

\section{RESULTS AND DISCUSSION}

\section{OMC and MDD characteristics}

Effect of municipal solid waste incinerator fly ash as a soil-sand mixture replacement. Mixtures of the OMC and MDD with $0 \%, 7 \%, 14 \%, 21 \%$ and $28 \%$ of MSWIFA. The inclusion of MSWIFA deceases the rise MDD and increases the OMC correspondingly. With the proportion of MSWIFA from 0 to $28 \%$, the OMC raise from $11.09 \%$ to $12.98 \%$ and the MDD reduce from $1940 \mathrm{~kg} / \mathrm{m} 3$ to $1812 \mathrm{~kg} / \mathrm{m} 3$. 
Table.6. Phase I and Phase II test result for OMC and MDD

\begin{tabular}{|c|c|c|c|c|c|}
\hline \multicolumn{3}{|c|}{ Phase I } & \multicolumn{3}{c|}{ Phase II } \\
\hline Sample & OMC \% & MDD $\left(\mathrm{kg} / \mathrm{m}^{3}\right)$ & Mix & OMC \% & MDD $\left(\mathrm{kg} / \mathrm{m}^{3}\right)$ \\
\hline IF & 11.09 & 1940 & E1 & 13.21 & 1891 \\
IF7 & 11.78 & 1911 & E2 & 13.47 & 1828 \\
IF14 & 12.23 & 1876 & E3 & 14.32 & 1767 \\
IF21 & 12.51 & 1841 & E4 & 14.98 & 1719 \\
IF28 & 12.98 & 1812 & E5 & 15.12 & 1678 \\
& & & E6 & 15.45 & 1626 \\
\hline
\end{tabular}

\section{Effect of soil-sand mixtures of the MSWIFA particle size and quantity}

The impact on the OMC and MDD soil-sand-cement mixes and substitution of MSWIFA are shown in Table 6. The MDD decreases and OMC increases with MSWIFA substitution in comparison to the control mix, for phase II. The MDD and OMC values for $0 \%, 20 \%, 40 \%$, $60 \%, 80 \%$, and $100 \%$ replacement ratios of MSWIFA particle size between 0/4.75 mm (E) are $1891 \mathrm{~kg} / \mathrm{m} 3-1625 \mathrm{~kg} / \mathrm{m} 3$ and $13.21-15.45 \%$, respectively, when sand is substituted by MSWIFA particles with sizes ranging from 0 to $4.75 \mathrm{~mm}(\mathrm{E})$. Among 20\%, 40\%, 60\%, 80\%, and $100 \%$ replacement ratios E2 seemed to have the highest MDD value (20\% of the sand was replaced by MSWIFA particles with sizes ranging from 0 to $4.75 \mathrm{~mm}$ ).

\section{Dry and Wet compressive strength}

\section{Effect of municipal solid waste incinerator fly ash as a soil-sand mixture replacement}

After 28 days of curing, the dry and wet compressive strength of CSEBs is shown in Fig. 5. (a). It can be shown that adding MSWIFA to the mix increases compressive strength considerably when compared to the control sample; this finding is consistent with previous research. Table 7 with the average dry compression strength obtained in the range $7.32-8.61$ $\mathrm{MPa}$ and the wet compressive strength achieved in the range 5.89-7.56 MPa which was corresponding to $0-28 \%$ of MSWIFA. In order to better understand the distributed size of mixes in particles, there is an obvious correlation between the coefficient of uniformity and curvatures and the compressive strength. The use of MSWIFA fines to fill the spaces between sand particles, as well as a reduction in clay content, were expected to increase cement with 
sand grain efficiency [14]. These findings are consistent with previous research that found a loss of 5-20\% for soil-sand-lime-rice hush-ash mixtures[16] and a loss of 19-33\% for cement-stable soil-grained blast-furnace slag blends[5], respectively, where a loss of strength ranged from 10 to $23 \%$ for samples and $30 \%$ ceramic waste. [18][19].

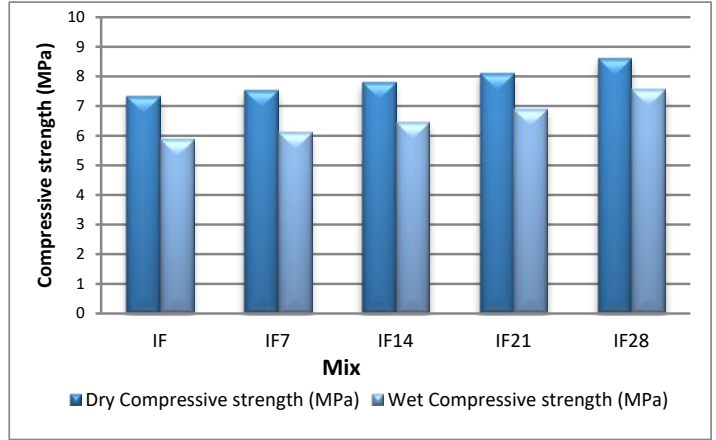

(a) Phase I block Compressive strength

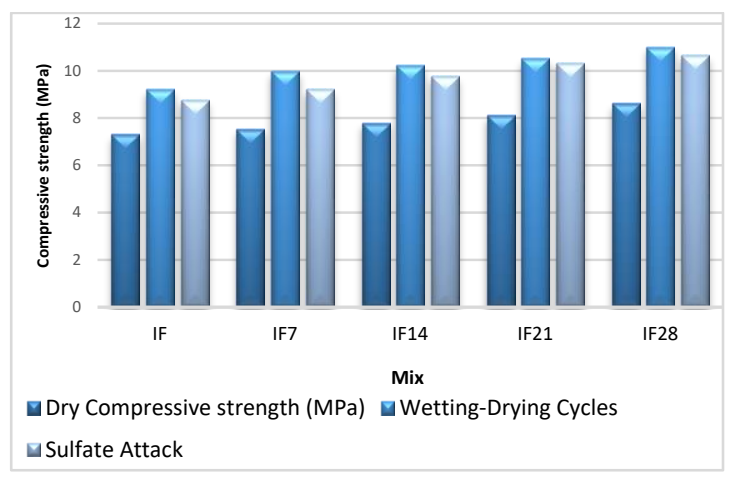

(c) Phase I block Compressive strength before and after sulphate attack and wetting-drying cycle cycle

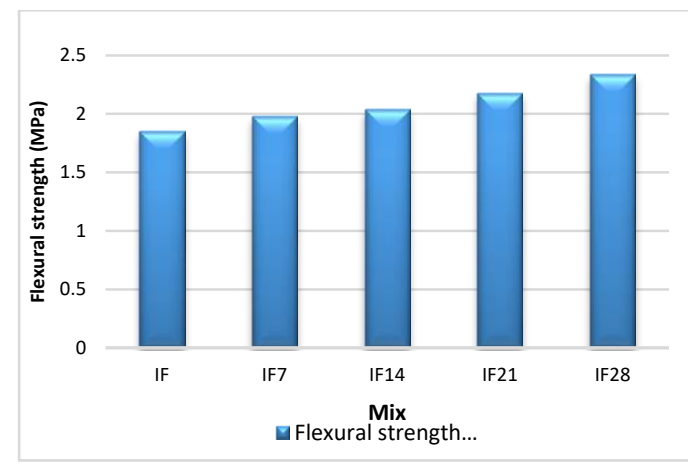

(b) Phase I block Flexural strength

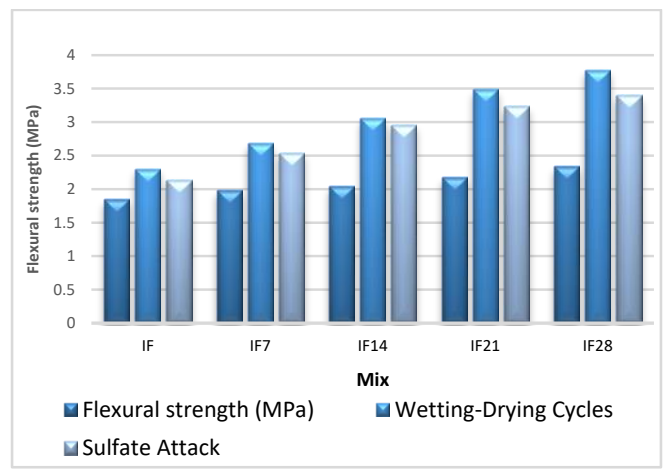

(d) Phase I block Flexural strength before and after sulphate attack and wetting-drying

Figure.5. Phase I results

\section{Effect of soil-sand mixtures of the MSWIFA particle size and quantity}

The compression strength of blocks with of MSWIFA is shown in 8. The results show that blocks with size of MSWIFA lower their strength, with the proportion of substitution increasing relative to the control sample. Initially the strength of the $\mathrm{E}$ (manufactured from 0/4.75 mm MSWIFA) blocks increased for $20 \%$ substitution, but subsequently slowly decreased for further substitution. Due to the combined impact of pozzolanic effects and the filing effect of MSWIFA fines, the strength of E2 was increased [17]. The decrease in strength at larger replacements, might be attributed to a rise in fines content, which increases porosity, in addition to the weaker characteristics of MSWIFA compared to sand. The compressive test of block shown in Fig.6.[20]. 
(a)

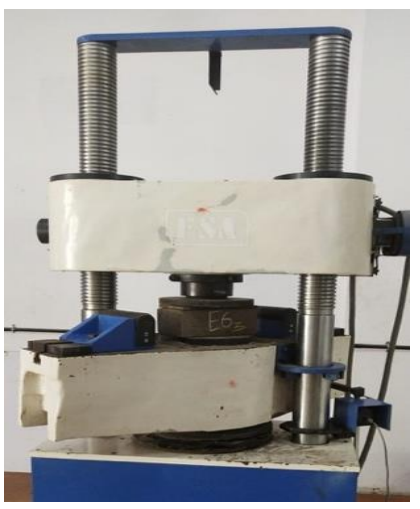

(b)

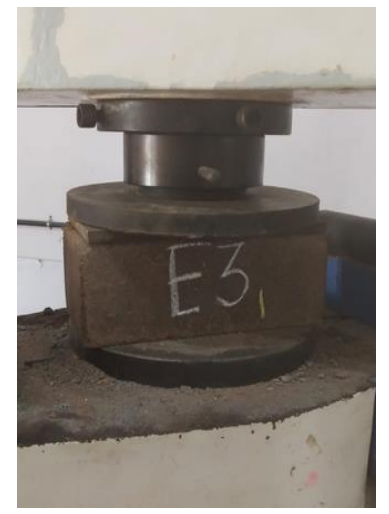

Figure.6. (a) \& (b). Compressive test of block

The strength improved in E2 was predicted due to the presence of fines. The incinerator solid waste, generally is less than $75 \mathrm{~mm}$ reactive due to high-temperature burning[21]. These results show that the size of the MSWIFA particle has significant impact on the strength of the block. The mixture's particle size distribution was also considered in order to explain the trend in strength with the substitution rate for MSWIFA[22]. The compressive strength of E2 is generally stronger in dry and wet conditions, but in wet conditions decreases dramatically[23].

Table.7. Results of Phase I

\begin{tabular}{|l|c|c|c|c|c|}
\hline Sample & $\begin{array}{c}\text { Dry } \\
\text { Compressive } \\
\text { strength (MPa) }\end{array}$ & $\begin{array}{c}\text { Wet } \\
\text { Compressive } \\
\text { strength (MPa) }\end{array}$ & $\begin{array}{c}\text { Flexural } \\
\text { strength (MPa) }\end{array}$ & $\begin{array}{c}\text { Water } \\
\text { absorption (\%) }\end{array}$ & $\begin{array}{c}\text { Wet-Dry } \\
\text { strength } \\
\text { ratio }\end{array}$ \\
\hline IF & 7.32 & 5.89 & 1.85 & 7.49 & 0.80 \\
IF7 & 7.54 & 6.12 & 1.98 & 7.92 & 0.81 \\
IF14 & 7.80 & 6.45 & 2.04 & 8.34 & 0.82 \\
IF21 & 8.11 & 6.89 & 2.18 & 8.89 & 0.84 \\
IF28 & 8.61 & 7.56 & 2.34 & 9.02 & 8.87 \\
\hline
\end{tabular}

\section{Flexural strength}

\section{Effect of municipal solid waste incinerator fly ash as a soil-sand mixture replacement}

Flexural strength of blocks containing municipal solid waste incinerator fly ash was greater than the control, similar to compressive strength behaviour. The flexural strength blocks are 
shown in Table 7. The greatest strength of $2.34 \mathrm{MPa}$ was achieved for blocks made with $28 \%$ MSWIFA, as illustrated in Fig. 5(b). The division into two halves under a three-point load failed all blocks.

\section{Effect of soil-sand mixtures of the MSWIFA particle size and quantity}

The flexural strength of blocks containing MSWIFA is shown in Table 8 and Fig. 8. Except for the E2-20\% block, the flexural strength of blocks decreases as the replacement percentage rises. The greatest flexural strength found for 20CF blocks was $2.57 \mathrm{MPa}$, which is $16 \%$ more than the control sample value. In addition to E2-20\% blocks are decreasing in strength from $40 \%$ to $100 \%$ for MSWIFA. The flexural strength was clearly harmed by the use of extremely fine MSWIFA in higher proportions. In all, the CSEBs were over the required flexural strength of $0.25 \mathrm{MPa}$ for load-bearing masonry. It was concluded that the elimination of fines from MSWIFA did not have any significant impact on the flexural strength. In turn, MSWIFA and its replacement percentage have impacted the strength of the block considerably. For the combination, $20 \%$ of MSWIFA in particle size 4.75 to $0 \mathrm{~mm}(20 \%$ E2) was achieved the optimal strength.

Table.8. Results of Phase II

\begin{tabular}{|c|c|c|c|c|c|}
\hline Sample & $\begin{array}{c}\text { Dry } \\
\text { Compressive } \\
\text { strength (MPa) }\end{array}$ & $\begin{array}{c}\text { Wet } \\
\text { Compressive } \\
\text { strength (MPa) }\end{array}$ & $\begin{array}{c}\text { Flexural } \\
\text { strength (MPa) }\end{array}$ & $\begin{array}{c}\text { Water } \\
\text { absorption (\%) }\end{array}$ & $\begin{array}{c}\text { Wet-Dry } \\
\text { strength } \\
\text { ratio }\end{array}$ \\
\hline E1 & 8.51 & 7.34 & 2.91 & 8.50 & 0.86 \\
E2 & 7.92 & 7.11 & 2.57 & 9.87 & 0.89 \\
E3 & 7.51 & 6.76 & 2.09 & 10.91 & 0.90 \\
E4 & 7.25 & 6.54 & 1.98 & 12.21 & 0.90 \\
E5 & 6.5 & 5.12 & 1.76 & 13.01 & 0.78 \\
E6 & 5.9 & 4.57 & 1.21 & 14.78 & 0.77 \\
\hline
\end{tabular}

\section{Water absorption}

\section{Effect of municipal solid waste incinerator fly ash as a soil-sand mixture replacement}

With the increase in the contents of MSWIFA, water absorption of the phase I blocks increases from $7.49 \%$ to $9.02 \%$, with the dosage of municipal solid waste incinerator fly ash increasing from 0 to 28\%.as shown in Fig. 7 and Table 7. 


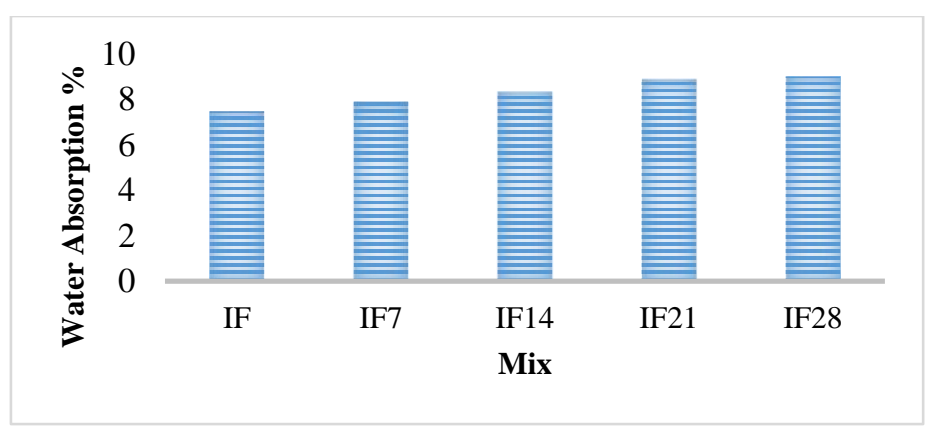

Figure.7. Water absorption results of Phase I

\section{Effect of soil-sand mixtures of the MSWIFA particle size and quantity}

Figure 8 show the effect of MSWIFA size and replacement ratio on block water absorption. The data shows that water absorption rises with increasing percentage replacement. For 0/4.75 mm (E) blocks, water absorption values of E1, E2, E3, E4, E5, E6 are higher than the control blocks. Sand may be substituted with MSWIFA in this experiment instead of soil since these changes are possible. It shows the integration of fine, MSWIFA that results in greater absorption. The wet compressive strength behaviour is confirmed by these data. As the replacement percentage ranges from $20 \%$ to $100 \%$, the increase in water absorption values is roughly $\pm 6 \%$. However, the inclusion of fines in $\mathrm{E}$ mixes enhanced the microstructure by pores filling and reacting with calcium hydroxide, which led to the thick matrix, reducing water absorption. This may be due to the filling of gaps with municipal solid waste that hinders block water entry, but this impact was no longer seen when replacing more than $40 \%$. This might be due to vacuums being filled with MSWIFA fines preventing the water entry into the block, whereas this impact was no longer seen at above $40 \%$ replacement. This was mainly due to greater water absorption of finer particles than MSWIFA rougher particles. Overall, in one hand, there were little variations in water absorption when the powder content was removed. The finer the particle size of the MSWIFA, the greater the water absorption, and its dependence on particle size were verified. 


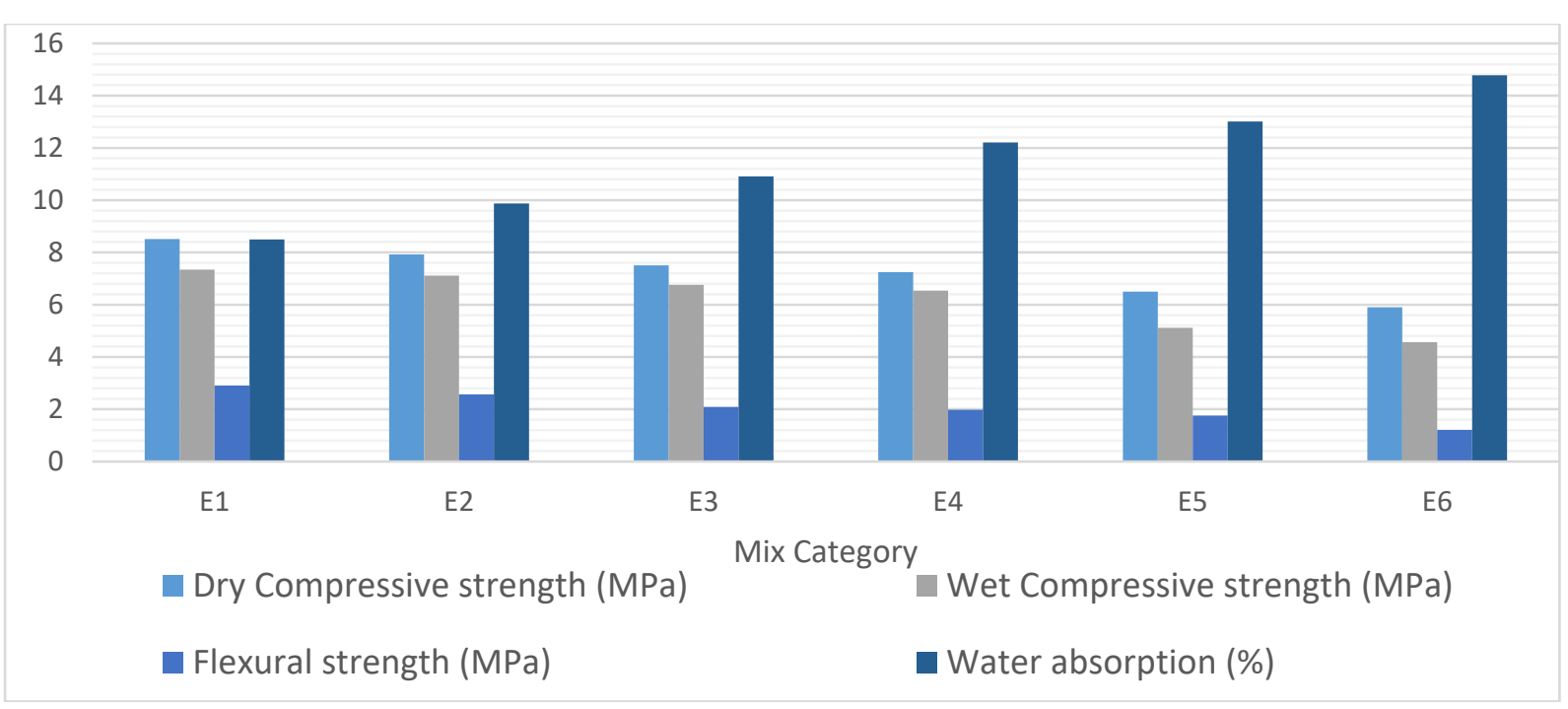

\section{Durability tests}

Figure.8. Phase II blocks result

\section{Wetting-Drying resistance}

Blocks were checked for any cracks, once testing has been completed. The little damage of surface and angle particles occurred in the entire block. However, due of strong adhesion between particles and matrices, blocks containing MSWIFA demonstrate a greater abrasion resistance. These blocks were tested for compressive and flexural strength in order to assess the mechanical performance. The results are shown in Fig. 5 (c) and (d), Table 9. Blocks made with $28 \%$ of MSWIFA attained the maximum strength of $11.01 \mathrm{MPa}$ (E28). After wetting-drying tests, control block strength was increased, similarly for blocks containing MSWIFA of 7 to $28 \%$ the improvement in strength (Table 9). The compressive strength of 7 $28 \%$ MSWIFA in blocks is higher than control. The strength values for blocks containing 028\% MSWIFA were typically between 2.30 and 3.49 MPa. Also, as compared to controlling the flexural strength, the MSWIFA is increased by around from 7 to $28 \%$. 
Table.9. Sulfate Attack and Wetting-Drying cycle of Phase I blocks

\begin{tabular}{|l|c|c|c|l|}
\hline \multirow{2}{*}{ Sample } & \multicolumn{2}{|c|}{ Wetting-Drying Cycles } & \multicolumn{2}{c|}{ Sulfate Attack } \\
\cline { 2 - 5 } & $\begin{array}{l}\text { Dry } \begin{array}{c}\text { compressive } \\
\text { strength (MPa) }\end{array} \\
\text { Flexural strength } \\
\text { (MPa) }\end{array}$ & $\begin{array}{l}\text { Dry compressive } \\
\text { strength (MPa) }\end{array}$ & $\begin{array}{l}\text { Flexural strength } \\
\text { (MPa) }\end{array}$ \\
\hline IF & 9.22 & 2.30 & 8.78 & 2.14 \\
IF7 & 9.98 & 2.68 & 9.21 & 2.54 \\
IF14 & 10.23 & 3.06 & 9.76 & 2.96 \\
IF21 & 10.53 & 3.49 & 10.34 & 3.24 \\
IF28 & 11.01 & 3.78 & 10.65 & 3.40 \\
\hline
\end{tabular}

\section{Sulfate resistance}

On the blocks there were no obvious damages/spalling. But on control block edges and sides a small layer of florescence formed. While there was no indication of efflorescence for blocks made from municipal solid waste incinerator fly ash. The results of $0-28 \%$ percent MSWIFA blocks before and after exposure to sodium sulphate $\left(\mathrm{Na}_{2} \mathrm{SO}_{4}\right)$ solution are given in Fig.5 (c) and (d). The compressive strength was greater than the initial value recorded at 28 days of air curing, all blocks subjected to sulphate attack. The block with a 28\% MSWIFA of $10.65 \mathrm{MPa}$ has the maximum strength. After 2 cycles in $\mathrm{Na}_{2} \mathrm{SO}_{4}$ solution, the compressive strength of the blocks rises. Similarly, the strength increase following $\mathrm{Na}_{2} \mathrm{SO}_{4}$ exposure for blocks of 7-28\% MSWIFA (Table 9). The flexural strength of blocks subjected to $3 \% \mathrm{Na}_{2} \mathrm{SO}_{4}$ increased. As the amount of MSWIFA ranges 0-28\%, strength levels range from 2.14 MPa to 3.40 MPa as shown in Fig. 5(d). With 7\%, 14\%, 21\% and 28\%of MSWIFA, the flexural strength of the blocks than the control. Usually, after sulfate has been added into cement, this reacts to gypsum \& ethringite mostly extensive in nature with the portlandite and aluminium phases. 


\section{CONCLUSIONS}

An in-depth experimental research was carried out to analyse the effects of municipal solid waste incinerator fly ash on the characteristics of compressed stabilized earth blocks to replace the soil-sand mix and its particle size and substitution ratios. As the percentage of MSWIFA increases, the OMC increases and MDD reduces. MSWIFA added up to $28 \%$ increased compressive (wet-dry) and flexural strengths. The strengths of sulfate exposure enhanced significantly during wetting-drying cycles due to the production of more compounds. The $28 \%$ block of municipal solid waste incinerator fly ash had the best mechanical strength and improved durability. Water absorption of blocks rises when the MSWIFA percentage increases in phases I and II, regardless of particle size. At a replacement amount of sand of $100 \%$ by fine MSWIFA, the maximum water absorption was observed (100E6).Further research will thus be necessary in order to evaluate block longterm durability. The current study has proven a possibility for the manufacturing of compressed earth blocks of soil-sand mixing and sand replaced with MSWIFA without affecting mechanical and durability performance.

\section{REFERENCE}

[1] Nagaraj H B, Rajesh A and Sravan M V 2016 Influence of soil gradation , proportion and combination of admixtures on the properties and durability of CSEBs Constr. Build. Mater. 110 135-44

[2] Nagaraj H B and Shreyasvi C 2017 Compressed stabilized earth blocks using iron mine spoil waste - An explorative study Procedia Eng. 180 1203-12

[3] $\mathbf{H b ~ N}, \mathbf{K v}$ A and Nc D 2018 Utilization of granite sludge in the preparation of durable compressed stabilized earth blocks 4 237-43

[4] Cottrell J A, Ali M, Tatari A and Martinson D B 2021 An investigation into the influence of geometry on compressed earth building blocks using finite element analysis Constr. Build. Mater. 273121997

[5] Sekhar D C and Nayak S 2018 Utilization of granulated blast furnace slag and cement in the manufacture of compressed stabilized earth blocks Constr. Build. Mater.1665316

[6] Concrete G, Block I and Agricultural F 2016 Investigation of compressed earth brick containing ceramic waste INVESTIGATION OF COMPRESSED EARTH BRICK CONTAINING 
[7] Jesudass A, Gayathri V, Geethan R, Gobirajan M and Venkatesh M 2020 Earthen blocks with natural fibres - A review Mater. Today Proc. 45 6979-86

[8] Munir M J, Abbas S, Nehdi M L, Kazmi S M S and Khitab A 2018 Development of Eco-Friendly Fired Clay Bricks Incorporating Recycled Marble Powder 30 1-11

[9] Gavali H R, Ram S and Ralegaonkar R V 2018 Evaluation of Energy Efficient Sustainable Walling Material 227-33

[10] Marieta C, Guerrero A and Leon I 2021 Municipal solid waste incineration fly ash to produce eco-friendly binders for sustainable building construction Waste Manag. $120114-24$

[11] Sun J, Zhou H, Jiang H, Zhang W and Mao L 2021 Recycling municipal solid waste incineration fly ash in fired bricks : An evaluation of physical-mechanical and environmental properties Constr. Build. Mater. 294123476

[12] Ravi M, Murugesan B, Jeyakumar A and Raparthi K 2021 A Review on Utilizing the Marine Biorefinery Waste in Construction Raw Materials to Reduce Land Pollution and Enhance Green Environment Adv. Mater. Sci. 21 43-62

[13] Corinaldesi V, Donnini J and Nardinocchi A 2015 Lightweight plasters containing plastic waste for sustainable and energy-efficient building Constr. Build. Mater. 94 $337-45$

[14] Elahi T E, Rafat A, Alam K and Abedin Z 2020 Effectiveness of saw dust ash and cement for fabrication of compressed stabilized earth blocks Constr. Build. Mater. 259 120568

[15] Subramanian G K M, Balasubramanian M and Kumar A A J 2021 A Review on the Mechanical Properties of Natural Fiber Reinforced Compressed Earth Blocks https://doi.org/10.1080/15440478.2021.1958405

[16] Kasinikota P and Tripura D D 2021 Evaluation of compressed stabilized earth block properties using crushed brick waste $\mathbf{2 8 0}$

[17] Gurumoorthy C and Shanmugapriyan R 2020 Compressed Stabilized Earth Block using Fly Ash and Quarry Dust 714-6

[18] Seco A, Omer J, Marcelino S, Espuelas S and Prieto E 2018 Sustainable unfired bricks manufacturing from construction and demolition wastes Constr. Build. Mater. $167154-65$

[19] Assia Z, Fazia F and Abdelmadjid H 2019 Sustainability of the stabilized earth blocs under chemicals attack' s effects and environmental conditions Constr. Build. Mater. 212 787-98 
[20] Corinaldesi V 2012 Environmentally-friendly bedding mortars for repair of historical buildings Constr. Build. Mater. 35 778-84

[21] Dinesh Kumar Raju S, Balasubramanian M and Arul Jeya Kumar A 2020 experimentalstudies on replacement of steel stirrups by sisal fiber reinforced polymers IOP Conf. Ser. Mater. Sci. Eng. 912

[22] Guru Kumar M S, Balasubramanian M and Arul Jeya Kumar A 2020 APPLICATION of FGC BLOCKS for SUSTAINABLE INFRASTRUCTURE DEVELOPMENT IOP Conf. Ser. Mater. Sci. Eng. 912

[23] Aarthy Reddy R, Balasubramanian M and Selvam G 2020 Analysis the effect of chromosome and generation count on genetic algorithm in construction projects: A case study IOP Conf. Ser. Mater. Sci. Eng. 912 